\title{
Downregulation of microRNA-1 and microRNA-145 contributes synergistically to the development of colon cancer
}

\author{
XUEHU XU ${ }^{1}$, XIAOBING WU ${ }^{1}$, QINGPING JIANG ${ }^{2}$, YAN SUN ${ }^{3}$, \\ HAIBO LIU $^{4}$, RONG CHEN ${ }^{1}$ and SHANGBIAO WU ${ }^{1}$ \\ Departments of ${ }^{1}$ Gastrointestinal Surgery, ${ }^{2}$ Pathology and ${ }^{3}$ Gastroenterology, \\ and ${ }^{4}$ Key Laboratory for Major Obstetric Diseases of Guangdong Province, The Third Affiliated Hospital \\ of Guangzhou Medical University, Guangzhou, Guangdong 510150, P.R. China
}

Received January 18, 2015; Accepted August 31, 2015

DOI: $10.3892 / \mathrm{ijmm} .2015 .2364$

\begin{abstract}
The aim of the present study was to identify the differentially expressed microRNAs (miRNAs or miRs) in patients with colon cancer and examine their roles in the pathogenesis of the disease. The expression profiles of miRNAs were examined in tumor tissue samples collected from 20 patients with histologically confirmed colon cancer and in the adjacent non-cancerous control tissues using microarray analysis. We found that numerous miRNAs were differentially expressed in the colon cancer tissues compared with the control tissues. Following functional analysis, we noted that three miRNAs which were significantly downregulated, miR-145, miR-451 and miR-1, shared the same target gene, [NLR family, apoptosis inhibitory protein (NAIP)], which has previously been reported to be involved in the development of colon cancer. We then confirmed that NAIP is a target gene of miR-145 and miR-1, but not of miR-451, using a luceriferase assay, and we confirmed the expression patterns of these miRNAs and NAIP in the tumor tissue, as well as in the adjacent non-cancerous control tissues. Additionally, in order to examine the function of miR-145 and miR-1 in human colon cancer, we transiently transfected a human colon cancer cell line with miR-145 and miR-1 mimics or inhibitors, and the results of MTT assay revealed that the re-expression of miR-145 and miR-1 inhibited the survival of colon cancer cells, which may be attributed to the inhibition of the anti-apoptotic activity of NAIP. Our findings demonstrated that miR-145 and miR-1 play a negative regulatory role in the proliferation of colon cancer by targeting NAIP; thus, miR-145 and miR-1 may prove to be novel therapeutic targets in the treatment of colon cancer.
\end{abstract}

Correspondence to: Dr Xuehu Xu, Department of Gastrointestinal Surgery, The Third Affiliated Hospital of Guangzhou Medical University, 63 Duobao Road, Guangzhou, Guangdong 510150, P.R. China

E-mail: coloncancer2@163.com

Key words: miR-1, miR-145, colon cancer, proliferation, apoptosis

\section{Introduction}

Colorectal cancer (CRC) is the third most common type of cancer worldwide (1). Even though the survival rate has doubled over the past 20 years, it remains one of the most fatal malignancies worldwide (2-4). CRC is a heterogeneous disease, and a complex series of molecular changes have been reported to be involved in the transformation of the normal colonic mucosa into a potentially invasive tumor over a long period of time (5). The development of CRC is generally believed to result from complex interactions between genetic and environmental factors (6). Molecular biomarkers based on gene mutations located in oncogenes or tumor suppressors, such as adenomatous polyposis coli (APC), v-raf murine sarcoma viral oncogene homolog B1 (BRAF) and p53 have been established for over a decade (6); however, the clinical applications of these biomarkers remain limited. For this reason, the development of novel molecular markers is necessary in order to improve the diagnosis, prognosis and treatment of CRC.

MicroRNAs (miRNAs or miRs) are a class of small non-coding RNAs, approximately 22 nucleotides in length, that post-transcriptionally regulate the expression of up to $1 / 3$ human genes. miRNAs target mRNAs through imperfect base pairing of the 5'-end of miRNAs to multiple sites in the 3 '-untranslated regions (UTRs) of the target transcript, and this imperfect miR-mRNA hybrid with central bulges (9-12 nt) recruits a microRNA ribonucleoprotein complex (miRNP) that enables the translational inhibition or exonucleolytic mRNA decay (7). More than half of the annotated human miRNAs have been found to be located in tumor-related chromosome segments or fragile hot spots that are predisposed to translocation, insertion or deletion in a number of human malignancies, including colon cancer (8), and thus, some miRNAs can function either as oncogenes or tumor suppressors (9-11).

Using microarray technology, we can detect the expression levels of thousands of genes simultaneously, which makes it a promising tool with which to discover novel potential diagnostic or therapeutic biomarkers, and it can assist us in exploring the underlying molecular mechanisms $(12,13)$. A growing body of evidence indicates that DNA microarray profiling performed on clinical specimens may be directly applied to cancer diagnosis, as well as to the evaluation of prognosis $(14,15)$. Additionally, 
expression profiling has been used to predict the response to cancer treatment (16). Expression profiling analysis has also been used to establish characteristic miRNA signatures that can predict the clinical outcomes of various malignancies (17).

In order to broaden our understanding of the molecular mechanisms underlying the pathogenesis of human CRC and explore novel potential biomarkers for use in clinical practice, in this study, we examined and compared gene expression profiles in CRC tissues and adjacent non-cancerous control tissues obtained from surgical resections, and using functional analysis, we focused on the differentially expressed miRNAs, their potential target gene, and their roles in regulating colon cancer cell behavior.

\section{Materials and methods}

Tissue sample collection. Paired primary CRC samples and adjacent histologically normal tissues were collected from a total of 60 patients with CRC in the Department of General Surgery at The Third Affiliated Hospital of Guangzhou Medical University (Guangdong, China). Tumor tissues and adjacent non-cancerous tissues that were at least $2.0 \mathrm{~cm}$ distal to the tumor margins were snap-frozen in liquid nitrogen and then stored at $-80^{\circ} \mathrm{C}$ until use. All samples were evaluated by two pathologists, according to the World Health Organization (WHO) guidelines (18). Those who had received chemotherapy or radiotherapy prior to surgery were excluded from this study. Informed consent was obtained from all patients, and the study was approved by the Human Research Ethics Committee of Guangzhou Medical University.

Gene expression analysis and data processing. RNA was isolated from each tissue sample and subjected to gene expression analyses using whole genome expression microarrays (Funeng Biotech Co., Ltd., Guangzhou, China). Following array data processing, differentially expressed genes were identified using the GeneSpring GX software package (Funeng Biotech), and only those miRNAs with differences $>1$.6-fold between the 2 groups (normal and tumor tisues) are listed in Table I.

In silico analysis. The target genes of the miRNA or the regulatory miRNA of certain genes were identified by searching online miRNA databases (www.TargetScan.org and www. miRanda.org). The candidate gene list was shortened based on their pathophysiological function.

RNA isolation and quantitative PCR ( $q P C R)$. Total RNA was isolated from HCT116 cells and tissues using the total RNA isolation kit (Invitrogen, Carlsbad, CA, USA). RNA was reverse transcribed into cDNA using the SuperScript III kit (Invitrogen). Total RNA concentrations were measured using a NanoDrop ND-1000 fluorospectrometer (NanoDrop Technologies, Wilmington, DE, USA). To confirm the differential expression of the selected miRNAs identified in our microarray analyses, standard SYBR-Green-based qPCR (Sigma-Aldrich, St. Louis, MO, USA) analyses were conducted. Specific primer sequences were as follows: miR-1 forward, 5'-aggcaaagagaatagttccccag-3' and reverse, 5'-cggacttcgt ggagatgga-3'; miR-145, forward, 5'-ctggctcttgataccccct-3' and reverse, 5'-tcaacactgagacgggctcc-3'; miR-451, forward, 5'-ggaaa ccaggaagcctagca-3' and reverse, 5'-tgattcagtgccattt tgcc-3'. Fluorescence was measured at the final step of each cycle using a real-time PCR system (ABI-7900; Applied Biosystems, Foster City, CA, USA). The housekeeping gene, U6, was used to normalize the expression data for the gene of interest.

Luciferase reporter assay. The human NLR family, apoptosis inhibitory protein (NAIP) 3'-UTRs were amplified by PCR and cloned into a modified version of pcDNA3.1(+) that contained a firefly luciferase reporter gene (Invitrogen), at a position downstream of the luciferase reporter. The vectors were termed wild-type 3'UTRs, and the primers for cloning the 3'-UTRs of NAIP were as follows: sense, 5'-GAT GAA TTC TTA TCC CCT GCC CCT TCC-3' and antisense, 5'-TAT CTC GAG TGG GTC CAC CAT GGC TAA GTG A-3'. Site-directed mutagenesis of the miRNA binding sites in the NAIP 3'UTR was performed using a Site-Directed Mutagenesis kit (SBS Genetech, Beijing, China) and termed mutant-1, -2 and -3 3'UTRs, as shown in Fig. 2. All constructs were confirmed by DNA sequencing. CRC cells (HCT116) were grown in a 48-well plate and co-transfected with $400 \mathrm{ng}$ of either individual miR mimics (miR-1, miR-145 or miR-451) or the control, $40 \mathrm{ng}$ of the firefly luciferase reporter plasmid including the 3'-UTR of the target gene, and 4 ng of pRL-TK, a plasmid expressing Renilla luciferase (Promega, Madison, WI, USA). After $24 \mathrm{~h}$, the cells were collected and the luciferase activity was determined using a TD-20/20 luminometer (Turner Biosystems, Sunnyvale, CA, USA).

Cell cycle and apoptosis analysis. At $48 \mathrm{~h}$ following transfection, the cells were collected by trypsinization and washed with phosphate-buffered saline (PBS). An Annexin-V-FLUOS Staining kit (Roche, Mannheim, Germany) was used to stain the cells, according to the manufacturer's instructions. Apoptosis was evaluated through fluorescence-activated cell sorting (FACS) using CellQuest software (Becton-Dickinson and Company, Franklin Lakes, NJ, USA), and Annexin-VFLUOS-positive cells were regarded as apoptotic cells. Flow cytometric analysis was performed using a Becton-Dickinson flowcytometer (BD Biosciences, San Jose, CA, USA).

Western blot analysis. The cells were lysed in RIPA lysis buffer [50 mM Tris-HCl, pH 8.0, $250 \mathrm{mM} \mathrm{NaCl}, 1 \% \mathrm{NP} 40$, $0.5 \%(\mathrm{w} / \mathrm{v})$ sodium deoxycholate, $0.1 \%$ sodium dodecylsulfate] (from Beyotime, Nanjing, China). The lysates were then centrifuged at $12,000 \mathrm{x} \mathrm{g} / \mathrm{min}$ at $4^{\circ} \mathrm{C}$ for $15 \mathrm{~min}$, and were subjected to $10 \%$ SDS polyacrylamide gel electrophoresis. The separated proteins were then transferred onto polyvinylidene difluoride membranes (Millipore, Billerica, MA, USA), and the membranes were subsequently incubated with primary antibodies at $4^{\circ} \mathrm{C}$ overnight and washed 3 times with PBS for $5 \mathrm{~min}$, followed by incubation with horseradish peroxidase-conjugated secondary antibodies (1:15,000 dilution; Cat. no. ZB-2301; Beijing Zhongshan Golden Bridge Biotechnology Co., Ltd., Beijing, China) at room temperature for $1.5 \mathrm{~h}$ and detected with an ECL kit (Applygen, Beijing, China). The primary anti-NAIP antibody (Cat. no. sc-11064; Santa Cruz Biotechnology, Santa Cruz, CA, USA), and anti- $\beta$ actin antibody (Cat. no. sc-47778; Santa Cruz Biotechnology) were diluted at 1:2,000. 
Table I. Differentially expressed microRNAs between cancerous tissues and adjacent non-cancerous control tissues, as identified by microarray analysis.

\begin{tabular}{|c|c|c|c|c|}
\hline \multirow[b]{2}{*}{ Gene } & \multicolumn{2}{|c|}{ Mean } & \multirow[b]{2}{*}{$\mathrm{t}$} & \multirow[b]{2}{*}{ P-value } \\
\hline & $\begin{array}{l}\text { Normal } \\
\text { tissues }\end{array}$ & $\begin{array}{l}\text { Tumor } \\
\text { tissues }\end{array}$ & & \\
\hline \multicolumn{5}{|l|}{ Downregulated } \\
\hline hsa-let-7c & 0.98 & -0.43 & 3.809 & 0.001 \\
\hline microRNA-126 & 2.8 & 1.56 & 3.852 & 0.001 \\
\hline microRNA-451 & 1.91 & 0.27 & 4.153 & 0.001 \\
\hline microRNA-23b & 2.7 & 1.14 & 4.394 & $<0.001$ \\
\hline microRNA-1979 & 1.79 & 0.47 & 4.453 & $<0.001$ \\
\hline microRNA-27b & 1.3 & -0.19 & 4.543 & $<0.001$ \\
\hline hsa-let-7b & 1.1 & -0.52 & 5.702 & $<0.001$ \\
\hline microRNA-125b & 1.43 & -0.37 & 6.202 & $<0.001$ \\
\hline microRNA-768-3p & 3.34 & 1.56 & 6.564 & $<0.001$ \\
\hline microRNA-99a & 3.79 & 1.83 & 6.73 & $<0.001$ \\
\hline microRNA-4770 & 3.17 & 0.91 & 7.162 & $<0.001$ \\
\hline microRNA-125a-5p & 2.66 & 0.84 & 7.195 & $<0.001$ \\
\hline microRNA-1 & 6.47 & 2.68 & 7.218 & $<0.001$ \\
\hline microRNA-100 & 3.45 & 1.58 & 7.294 & $<0.001$ \\
\hline microRNA-143 & 2.3 & -0.5 & 7.389 & $<0.001$ \\
\hline microRNA- $145^{*}$ & 8.42 & 4.99 & 7.897 & $<0.001$ \\
\hline \multicolumn{5}{|l|}{ Upregulated } \\
\hline hsa-let-21 & 0.96 & -0.49 & 3.901 & 0.001 \\
\hline microRNA-128 & 2.5 & 1.48 & 3.912 & 0.001 \\
\hline microRNA-375 & 2.01 & 0.24 & 4.024 & 0.001 \\
\hline microRNA-26b & 2.81 & 1.09 & 4.283 & $<0.001$ \\
\hline microRNA-146a & 1.81 & 0.46 & 4.503 & $<0.001$ \\
\hline
\end{tabular}

Cell culture. The human CRC cell line, HCT116, was purchased from the American Type Culture Collection (ATCC; Manassas, VA, USA). The HCT116 cells were cultured in Dulbecco's modified Eagle's medium (DMEM; Invitrogen) supplemented with $10 \%$ heat-inactivated fetal bovine serum (FBS; Invitrogen), $100 \mathrm{U} / \mathrm{ml}$ penicillin and $100 \mathrm{lg} / \mathrm{ml}$ streptomycin (Invitrogen), at $37^{\circ} \mathrm{C}$ in a $5 \% \mathrm{CO}_{2}$ atmosphere.

3-(4,5-Dimethylthiazol-2-yl)-2,5-diphenyltetrazolium bromide (MTT) assay. The HCT116 cells were transfected with miR-1 mimics and/or miR-145 mimics, or miR-1 inhibitors, or negative control (NC) and incubated for $48 \mathrm{~h}$. MTT soloution $(25 \mu \mathrm{l}$ $0.5 \%$; Sigma-Aldrich) was added to each well followed by incubation for a further $3 \mathrm{~h}$. The medium was then replaced with $150 \mu$ l dimethyl sulfoxide (DMSO; Sigma-Aldrich), which was added to the microplate, and shaken on a rotary platform for $15 \mathrm{~min}$. The cell survival rate was determined by measuring the optical density (OD) values at a $492 \mathrm{~nm}$ wavelength and comparing these values with the OD values of the controls.

RNA oligoribonucleotide and transfection. MicroRNA mimics were purchased from Dharmacon(Lafayette, CO,USA): miR-145 mimic (MIMAT0000437), miR-1 mimic (MIMAT0000416) and miR-451 mimic (MIMAT0001631). miRNA inhibitors were purchased from Guangzhou RiboBio Co., Ltd., Guangzhou, China: miR-1 inhibitor (miR10005824-1-2) and miR-145 inhibitor (miR20000437-1-5). The HCT116 cells were cultured to $70 \%$ confluence, and Lipofectamine 2000 (Invitrogen) was used to transfect the DNA or RNA.

Statistical analysis. Data are expressed as the means \pm SD. Statistical analysis was performed using the SPSS 19.0 software package (IBM Inc., Chicago, IL, USA). P-values were calculated using the two-tailed Student's t-test or one-way ANOVA. P-values $<0.05$ were considered to indicate statistically significant differences, and P-values $<0.01$ were considered to indicate highly significant differences.

\section{Results}

Microarray analysis of miRNAs differentially expressed in cancer and adjacent non-cancerous tissues from patients with $C R C$. To identify the miRNAs involved in the regulation of $\mathrm{CRC}$ cell proliferation, invasion and metastasis, we examined and compared the gene expression profiles of whole CRC tissues and adjacent non-cancerous mucosa obtained from surgical resections using an miRNA microarray platform (whole genome expression microarrays as described in the Materials and methods). Of the human miRNAs on the array, a variety of miRNAs exhibited a significant difference in expression between the cancerous and non-cancerous samples. Among these miRNAs, 5 were upregulated and 16 were downregulated by $>1.6$-fold, between the 2 groups (Fig. $1 \mathrm{~A}$ and Table I). In particular, miR-145 exhibited the most significant difference in expression, with a $\log 2$ reduction of 3.43 in the cancer tissues compared with the controls. By using in silico analsyis and searching online microRNA databases, we identified NAIP as a potential target of miR-145. Furthermore, we found that NAIP was also a possible shared target of two other significantly downregulated miRNAs, miR-1 and miR-451.

Microarray validation by $R T-q P C R$ of $m i R-145$, miR-1 and $m i R-451$ in $C R C$ tissues. To validate the miRNA microarray data and examine the expression patterns of the focused miRNAs and the target gene, we measured the expression of miR-145, miR-1 and miR-451 in an additional 40 CRC tissue samples by RT-qPCR. These were quantified using the $\Delta \Delta \mathrm{Ct}$ method together with the previous 20 samples. One of the tested samples was selected as the calibrator, and the relative expression value of this sample was set as 1 . As shown in Fig. 1B, we found that the basal expression levels of miR-145, miR-1 and miR-451 were significantly decreased in the tumor tissues as compared with the adjacent non-cancerous control tissues.

Expression patterns of NAIP in cancerous and non-cancerous tissues. To determine the clinical significance of the target gene of miR-145 and miR-1, we measured the NAIP mRNA and protein levels in 40 pairs of matched CRC specimens by qPCR and western blot analysis. The protein expression of NAIP was significantly upregulated in the CRC tissues compared with the adjacent non-cancerous tissues (Fig. 1C-E). 
A

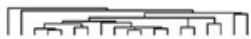

หู่

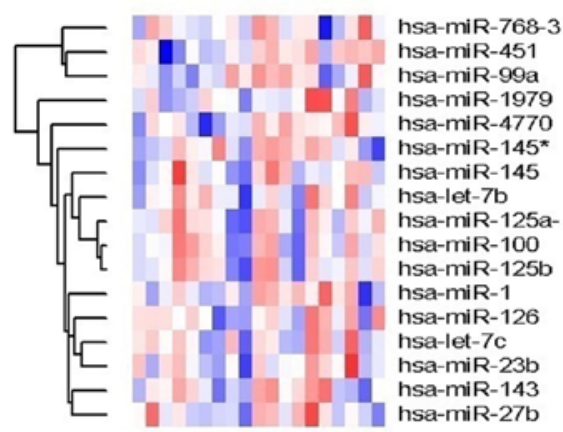

B

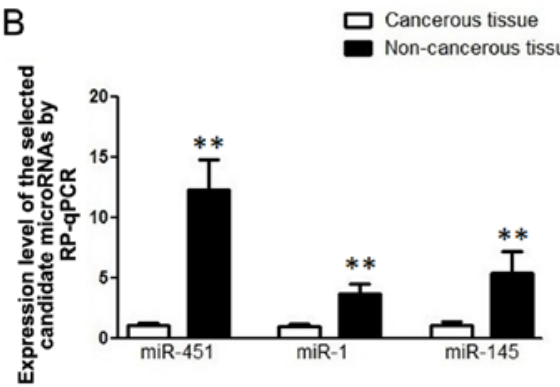

C

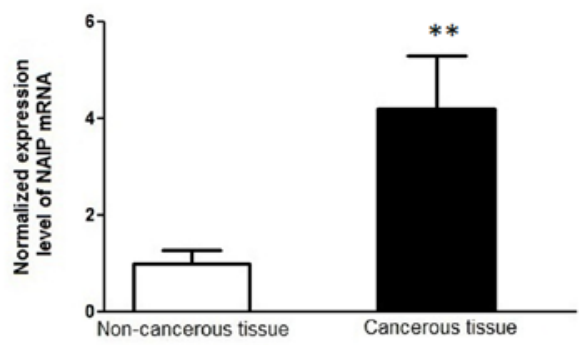

D NAIP

$\beta$-actin
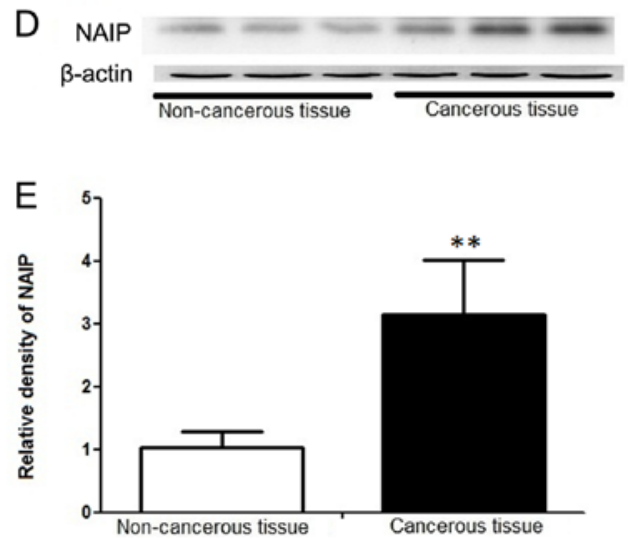

Figure 1. (A) Differentially expressed microRNAs identified using microarray analysis. (B) Expression patterns of miR-1, miR-145 and miR-451. (C) mRNA expression level of NLR family, apoptosis inhibitory protein (NAIP) mRNA in cancerous tissues vs. adjacent non-cancerous controls. (D) Protein expression level of NAIP in cancerous tissues vs. adjacent non-cancerous controls. (E) Densitometric analysis of the western blot analysis results. ${ }^{* *} \mathrm{P}<0.01$, compared to non-cancerous tissue.

A

Hsa-miR-1 targets NAIP

WT NAIP 3'UTR (1226-1232) 5' -AAGAUGGCGCCACUGCAUUCCAG-3'.

Hsa-miR-1

3 ' UAUGUAUGAAUAAAUGUAAGGU-5'

Mut1 NAIP 3'UTR (1226-1232) 5' -AAGAUGGCGOCACUGGUAGGGUG-3'

B

Hsa-miR-145 targets NAIP

WT NAIP 3'UTR (1443-1450) $\quad 5^{\prime}$-AUUAUACCUAAUDAAACUGGA-3'

Hsa-miR-145 IIIIIII

Mut2 NAIP 3'UTR (1443-1450) 5 ' -AUUAUACCUAandanugacCUA-3'
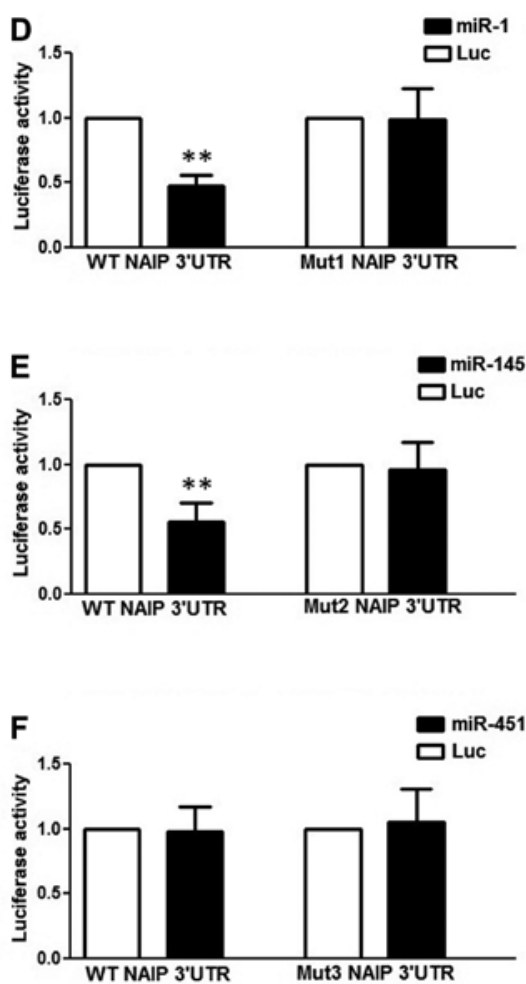

Figure 2. (A) Schematic representation of miR-1 and its binding sequence in the wild-type (WT) or mutant (mut) 3'-UTR of survivin mRNA; (B) schematic representation of miR-145 and its binding sequence in the WT or mut 3'-UTR of survivin mRNA; (C) schematic representation of miR-451 and its binding sequence in the WT or mut 3'-UTR of survivin mRNA; (D) analysis of luciferase activity in miR-1 overexpressing colorectal cancer (CRC) cells $48 \mathrm{~h}$ after co-transfection with the control Renilla luciferase expression construct pRL-TK and firefly luciferase reporter plasmids containing either WT or mut 3'-UTR of NLR family, apoptosis inhibitory protein (NAIP); (E) analysis of luciferase activity in miR-145 overexpressing CRC cells $48 \mathrm{~h}$ after co-transfection with the control Renilla luciferase expression construct pRL-TK and firefly luciferase reporter plasmids containing either WT or mut 3'-UTR of NAIP; (F) analysis of luciferase activity in miR-451 overexpressing CRC cells $48 \mathrm{~h}$ after co-transfection with the control Renilla luciferase expression construct pRL-TK and firefly luciferase reporter plasmids containing either WT or mut 3 '-UTR of NAIP. ${ }^{* *} \mathrm{P}<0.01$, compared to wild-type. 
A

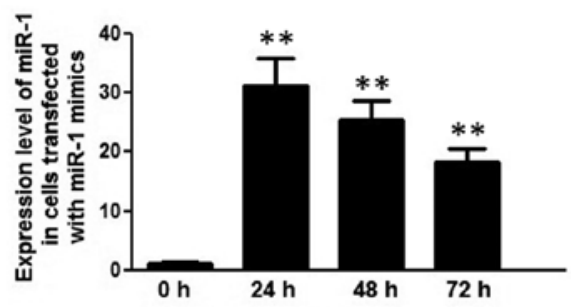

B

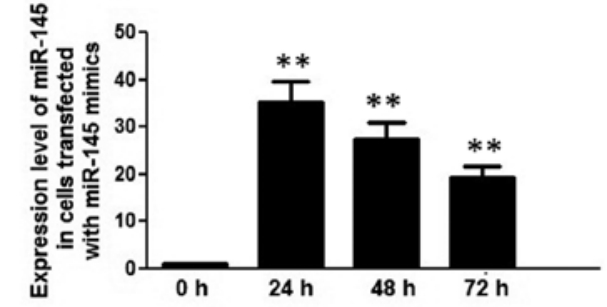

C

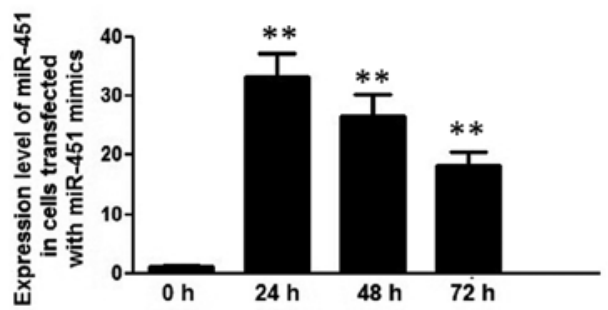

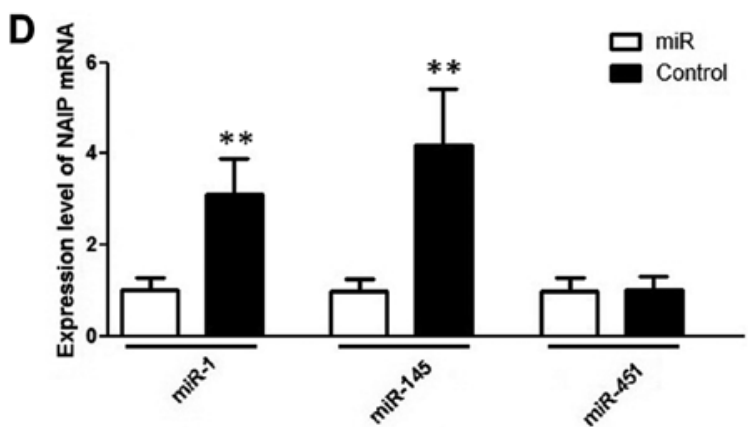

E

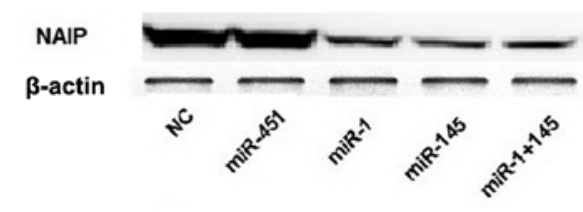

$\mathbf{F}$

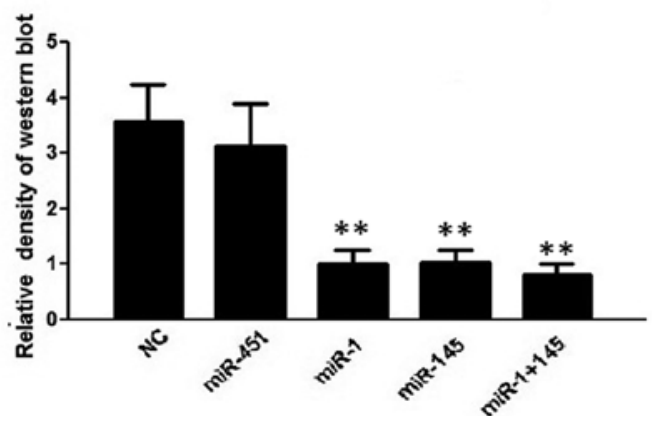

Figure 3. (A) Expression levels of miR-1 24, 48 and $72 \mathrm{~h}$ following transfection with miR-1 mimics; (B) expression levels of miR-145 24,48 and $72 \mathrm{~h}$ following transfection with miR-145 mimics; (C) expression levels of miR-451 24, 48 and $72 \mathrm{~h}$ following transfection with miR-451 mimics; ${ }^{* *} \mathrm{P}<0.01$, compared to the $0 \mathrm{~h}$ time point. (D) mRNA expression level of NLR family, apoptosis inhibitory protein (NAIP) following transfection with corresponding microRNAs; (E) protein expression level of NAIP following transfection with corresponding microRNAs, as determined by western blot analysis; (F) relative density of the western blot analysis results. ${ }^{* *} \mathrm{P}<0.01$, compared to control. $\mathrm{NC}$, negative control.

NAIP is a shared target of $m i R-145$ and $m i R-1$, but not $m i R-451$ in HCT116 cells. The aforementioned findings indicated that miR-145, miR-1 and miR-451 acted as a cell growth inhibitor in CRC tissues. Therefore, we searched for potential gene targets of miR-145, miR-1 and miR-451, which may contribute to its prometastatic function. We performed in silico analysis to search for the potential gene targets of miR-145, miR-1 and miR-451 using the bioinformatics algorithms, TargetScan (http:// www.targetscan.org/) and miRanda (http://www.microrna.org/ microrna/home.do). Both algorithms identified NAIP as a potential target gene of miR-145, miR-1 and miR-451 (Fig. 2A-C).

NAIP is a well-known inhibitor of apoptosis that promotes tumor growth. The above findings suggest that the oncogenic function of miR-145, miR-1 and miR-451 in CRC may be attributed to the suppression of NAIP expression. To examine this hypothesis, luciferase reporter assays were performed using luciferase reporters carrying the wild-type NAIP 3'-UTR, and we found that miR-145 and miR-1, but not miR-451, had a significantly decreased activity compared with the controls in the HCT116 cells (Fig. 2D-F).

Furthermore, the HCT116 cells transfected with miR-145, miR-451 and miR-1 mimics exhibited an approximately 30 -fold increase in each corresponding miR at $24 \mathrm{~h}$ following transfection compared with the controls ( 0 h) (Fig. 3A-C); however, only miR-1 and miR-145 decreased the mRNA and protein expression of NAIP in the HCT116 cells, and no such effect was observed in the cells transfected with the miR-451 mimic (Fig. 3D-F). These findings corroborate the hypothesis that NAIP expression has an inverse correlation with miR-145 and miR-1 expression, but not with miR-451 expression in CRC cells.

Additionally, miR-1 and miR-145 inhibitors were transfected into the HCT116 cells, but only the miR-1 inhibitor suppressed the expression level of miR-1, and endogenous miR-145 expression was already too low to be further reduced (Fig. 4A and B). As expected, the decrease in the expression of miR-1, caused by the miR-1 inhibitor, led to an increase in the protein and mRNA expression of NAIP in the HCT116 cells (Fig. 4C and D).

Upregulation of miR-1 and miR-145 inhibits HCT116 cell proliferation in vitro. To further examine whether the differentially expressed miRNAs alter the proliferative capacity of the HCT116 cells, miR-145 mimic, miR-1 mimic and miR-145 inhibitor were sequentially transfected into the HCT116 cells, and RT-qPCR was performed to determine miRNA upregulation or downregulation (Figs. 3A, 3B 

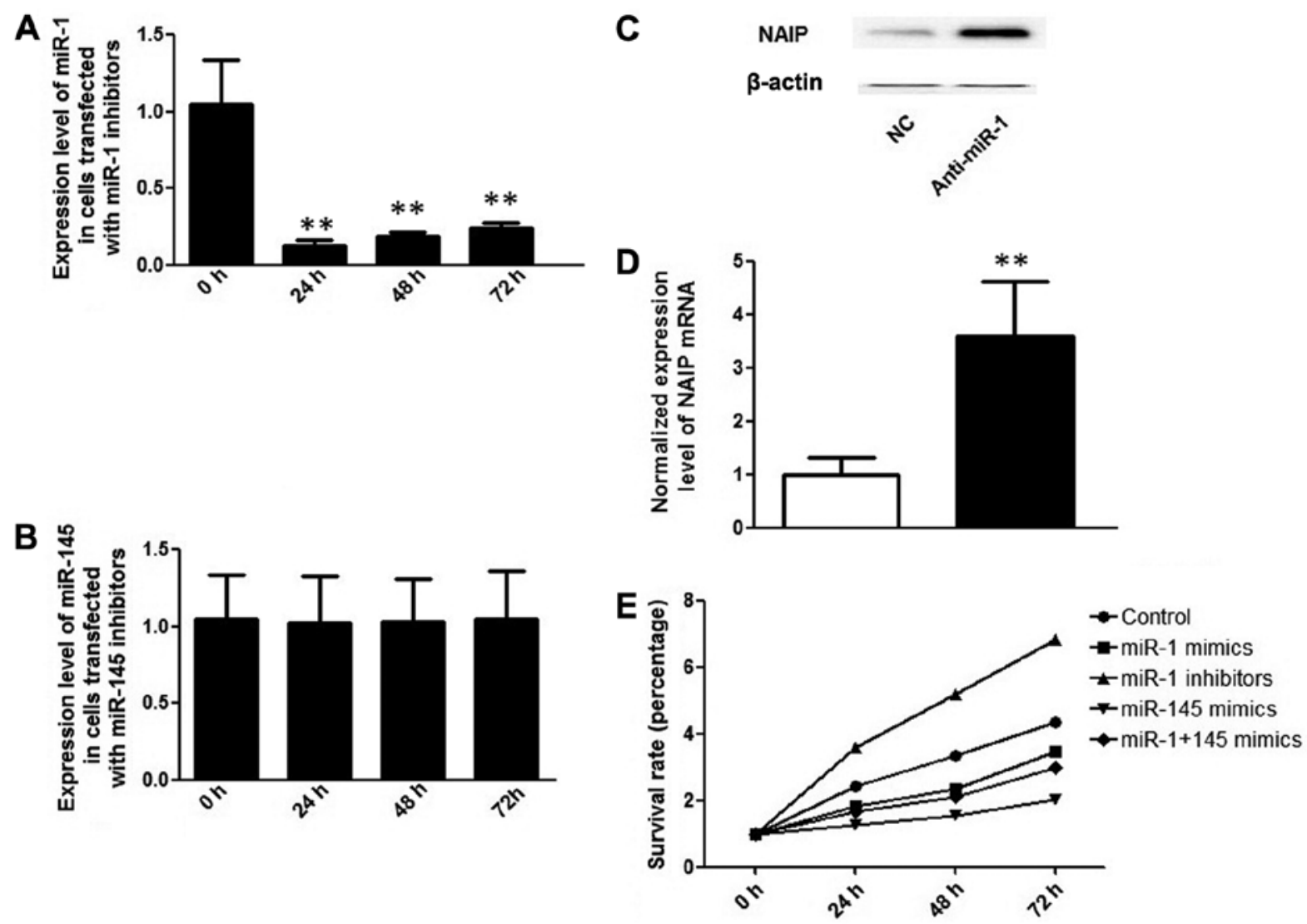

Figure 4. (A) Expression levels of miR-1 24, 48, 72 and $96 \mathrm{~h}$ following transfection with miR-1 inhibitors; (B) expression levels of miR-145 24, 48,72 and $96 \mathrm{~h}$ following transfection with miR-145 inhibitors; ${ }^{* *} \mathrm{P}<0.01$, compared to the $0 \mathrm{~h}$ time point. (C) protein expression level of NLR family, apoptosis inhibitory protein (NAIP) following transfection with miR-1 inhibitors; (D) mRNA expression level of NAIP following transfection with miR-1 inhibitors; ${ }^{* *} \mathrm{P}<0.01$, compared to control. (E) Survival rate analysis of colorectal cancer (CRC) cells transfected with miR-1 and/or miR-145 mimics, as determined by MTT assay 24,48 and $72 \mathrm{~h}$ following transfection. $\mathrm{NC}$, negative control.

and 4A). As shown in Fig. 4E, the overexpression of miR-145 and miR-1 significantly suppressed the proliferation of the HCT116 cells, as evidenced by a decrease in the percentage of surviving cells compared with the controls. The introduction of the miR-1 inhibitor evidently suppressed the expression of miR-1, causing an increase in NAIP expression (Fig. 4C) and promoting the proliferation of the cells (Fig. 4E).

Introducing miR-1 and miR-145 significantly induces the apoptosis of HCT116 cells. To elucidate the molecular mechanisms underlying the observed inhibitory effect on CRC cell proliferation of miR-1 and miR-145, we performed flow cytometric analysis using the cells transfected with miR-1 mimic and/or miR-145 mimic. We found that the introduction of miR-1 and miR-145 significantly induced apoptosis both individually and in combination, as shown in Fig. 5A-D, and the apoptotic status of the cells is summarized in Fig. 5E. Our results demonstrate that the inhibitory effect on CRC cell proliferation of miR-1 and miR-145 may be due to their ability to induce the apoptosis of HCT116 cells.

\section{Discussion}

CRC is a complex genetic disease which results from abnormalities in gene structure and/or expression (19). The aberrant expression of endogenous miRNAs has been noted in multiple types of human cancer, such as lung and breast cancer, leukemia and CRC (20), and the deregulated expression of certain miRNAs has been reported to be a marker for early diagnosis, prognosis, as well as the response to treatment in patients with CRC, indicating that miR-145 and miR-1 play a promising role as prognostic or therapeutic biomarkers for patients with CRC (21-23). The balance of oncogenes and tumor suppressor genes plays an essential role in regulating cell proliferation and survival $(24,25)$. Considering the fact that $1 / 3$ protein-coding mRNAs are subjected to miRNA-mediated regulation, the role of miRNAs in the development of malignancies is critical (26). In the present study, using microarray analysis, we identified 21 differentially expressed miRNAs, 5 upregulated and 16 downregulated mRNAs in the colon cancer samples as compared with the adjacent non-cancerous control tissues (Table I).

In non-cancerous tissue, miRNA-mediated control helps to maintain normal cell activities, including growth, differentiation and apoptosis. The deregulation of miRNA expression leads to the abnormal activity of the miRNA target genes, and the consequent upregulation of oncogene(s) and/or the downregulation of tumor suppressor gene(s) results in cells with selective advantages, such as increased proliferation or survival (27). The present study focused on individual miRNAs and their target genes. By using online target prediction tools, we identified NAIP as a possible shared target of three significantly downregulated miRNAs, miR-1, miR-145 and miR-451, 


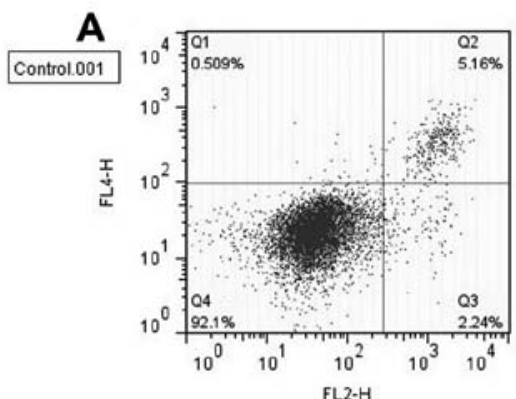

B
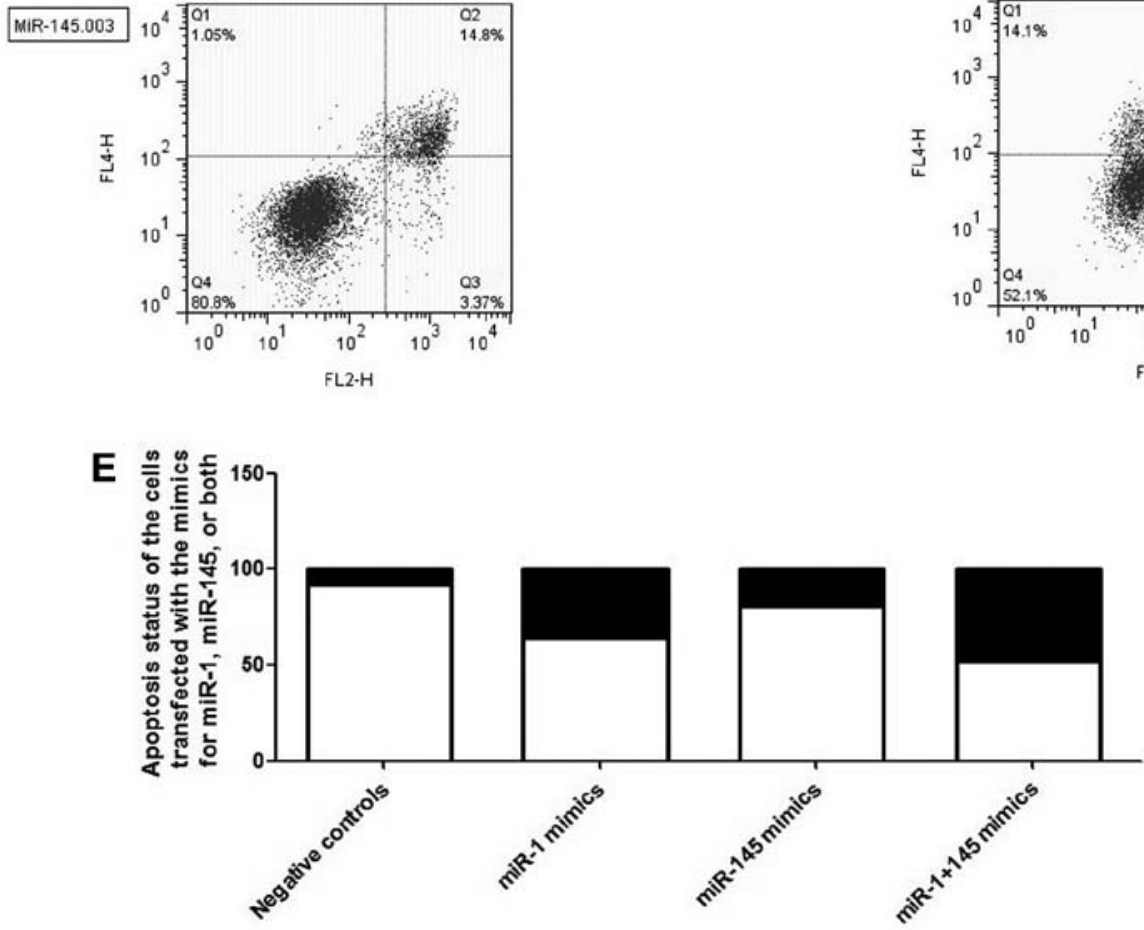

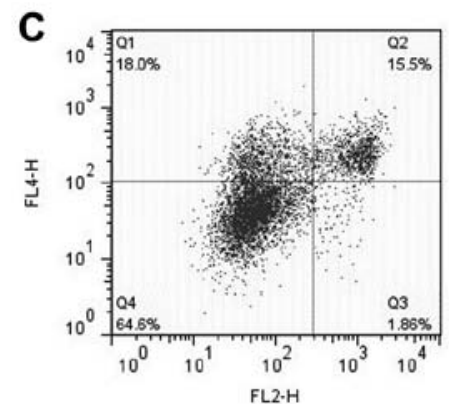

MR-1.002

D

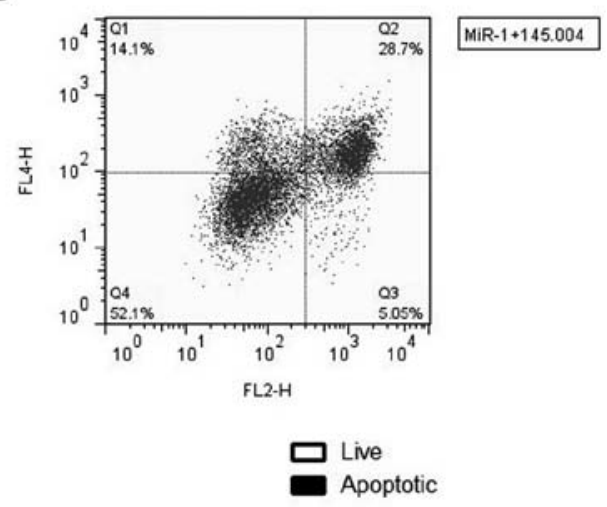

Figure 5. Effect of miR-1 and miR-145 mimics on the apoptotic status of colorectal cancer (CRC) cells. (A) Controls; (B) miR-145; (C) miR-1; (D) miR-1+miR-145; (E) chart of the apoptotic status of cells transfected with negative controls, miR-1 mimics, miR-145 mimics and miR-1 + miR-145 mimics.

and we subsequently demonstrated that NAIP is a valid target of miR-1 and miR-145, but not miR-451, using a luciferase assay (Fig. 2), and this was further confirmed by the observation that the introduction of miR-1 and miR-145 mimics decreased the expression level of NAIP (Fig. 3). miR-145 and miR-1 have been reported to be aberrantly expressed in numerous types of cancer, and their tumor-suppressive roles have been well established. miR-1 is located at $18 \mathrm{q} 11$ in the human genome, and is abundantly expressed in the heart and skeletal muscle tissue (28). It has been demonstrated that miR-1 is among the most frequently downregulated miRs in solid human tumors. miR-1 gene expression is reduced in human hepatocellular carcinoma cell lines compared to normal liver cells due to hypermethylation. When the miR-1 gene is hypomethylated, it re-expresses miR-1 and can induce apoptosis (29). In mouse myoblast cells, the mutant MyoD transcription factor downregulates miR-1 expression and inhibits cell apoptosis (30). miR-1 expression has bene shown to be downregulated in human lung cancer tissues and cell lines in comparison to normal human lungs, and miR-1 influences the response of lung cancer cells to anticancer drugs (31). Additionally, miR-1 is downregulated in human bladder cancer (32) and head-and neck squamous cell carcinoma (HNSCC) cells (33). It has been demonstrated that miR-1 acts as a tumor suppressor miRNA by directly targeting various oncogenes, such as prothymosin alpha (PTMA) and transgelin 2 (TAGLN2) (33).

miR-145 is located in a cluster in the $5 \mathrm{q} 32$ chromosomal region. Several mRNAs have been demonstrated to be direct targets of miR-145 (34) in colon cancer, and the dysregulation of this miRNA is believed to be responsible for the development of the disease. miR-145, or its analogue, has also been studied in relation to breast (35), leukemia (36), non-small cell lung (37) and prostate cancer (38). One of the best-characterized candidate targets of miR-145 is the oncogene cadherin-17 (CDH17), which is a member of the cadherin superfamily. Cadherins function as calcium-dependent cell adhesion proteins and their dysregulated expression is associated with tumor formation and metastasis (39). It has also been previously demonstrated that $\mathrm{CDH} 17$ is involved in proliferation, as it activates Wnt signaling (40). CDH17 was suppressed by $>2$-fold at the protein 
and mRNA level following transfection with miR-145 or its analogue miR-143 (40). Furthermore, it has been shown that chemically unmodified miR-145 complexed with polyethylenimine (PEI) can be used as an efficient and biocompatible strategy for miRNA replacement therapy, which is used in the treatment of colon cancer (41). In the present study, we confirmed the tumor suppressive effect of miR-145 and miR-1 by demonstrating the proliferation-suppressive and apoptosis-inducing effect of the mimics, as well as the proliferation-promoting effect of the inhibitors on CRC cells (Figs. 4 and 5). Moreover, we demonstrated that NAIP, a major anti-apoptotic protein, is an effective target gene of both miR-1 and miR-145 via a luciferase reporter system, and this was further confirmed by the observation that transfection with miR-1 and/or miR-145 suppressed the expression of NAIP.

As its name implies, the inhibitor of apoptosis (IAP) protein family plays an inhibitory role in the regulation of apoptosis and therefore, the overexpression of IAP family members is regarded as an unfavorable feature when diagnosing cancer (42). IAP family proteins are characterized by the presence of one or more baculovirus IAP-repeats (BIR) domains (43), which are zinc-binding folds approximately 70 amino acids long, including three conserved cysteine and one conserved histidine residue (44). The BIR domain is responsible for its ability to inhibit the function of apoptosis executioner caspase-3 and -7, as well as initiator caspase-9 by interacting with IAP-binding motifs (IBMs) in those proteins (43). In addition to the BIR domain, IAPs possess other domains, such as really interesting new gene (RING), caspase activation and recruitment domain (CARD) and nucleotide-binding oligomerization domain (NOD), the presence of which endow IAPs with additional abilities to regulate other accessory biological activities, including cell differentiation, cell cycle progression, cell signal transduction, and immune responses (43). The NAIP/baculoviral IAP repeat-containing protein 1 (BIRC1) gene coding region spans 4,212 nucleotides encoding a 1,403-amino acid protein of the $156 \mathrm{kDa}$ protein, and it contains 3 sequential BIR domains at the $\mathrm{N}$-terminus, which makes it quite typical among other IAPs.

In addition to the BIR domain, NAIP harbors a NOD and a leucine-rich repeat (LRR) $(45,46)$, which makes NAIP function differently from other IAP proteins (43). Due to the presence of the NOD domain and LRR motif, NAIP possesses the properties of both the IAP protein family and the nucleotide-binding domain and leucine-rich repeat containing (NLR) protein family. The NOD domain is essential for oligomerization, a key step in signal transduction, and the LRR domain functions as an intracellular sensor of microbial motifs (47). NAIP, together with some other members of NLR, promotes the synthesis and control of the cytoplasmic multiprotein complex termed 'inflammasome' (47). Considering the significant role that NAIP plays in regulating the inflammatory repsonse as well as the fact that miR-145 is substantially downregulated in patients with ulcerative colitis, it has been postulated that miR-145 may contribute to the pathogenesis of ulcerative colitis and is possibly involved in the mechanisms underlying the malignant transformation of the colonic epithelium into ulcerative colitis (48).

In summary, our data provide evidence that miR-1 and miR-145, which were found to be downregulated in colon carcinoma tissues, are involved in the multistep process of
CRC development through the modulation of NAIP expression, which in turn affects cell apoptosis. Furthermore, in CRC cells, miR-1 and miR-145 induce cell death by targeting a major antiapoptotic protein, NAIP, and contribute to the development of colon cancer. Therefore, both miR-1/miR-145 and NAIP can be regarded as having great potential in colon cancer therapy, and can be targeted by either re-expressing the miRNAs and/or interfering with NAIP function.

\section{Acknowledgements}

The present study was fully sponsored by the following three programs: the Guangzhou City Science and Technology and Information Bureau Science and Technology Supporting Program (grant no. 2010J-E141), the Guangdong Province, the Third Batch of Major Science and Technology Projects (grant no. 2011A080300002), and the Academic-Industrial Department of Guangdong Province Supported Pilot project (grant no. 2011B090400526).

\section{References}

1. Jemal A, Murray T, Samuels A, Ghafoor A, Ward E and Thun MJ: Cancer statistics, 2003. CA Cancer J Clin 53: 5-26, 2003.

2. Pasetto LM, Jirillo A, Iadicicco G, Rossi E, Paris MK and Monfardini S: FOLFOX versus FOLFIRI: a comparison of regimens in the treatment of colorectal cancer metastases. Anticancer Res 25: 563-576, 2005.

3. Goldberg RM and Gill S: Recent phase III trials of fluorouracil, irinotecan, and oxaliplatin as chemotherapy for metastatic colorectal cancer. Cancer Chemother Pharmacol 54 (Suppl 1): S57-S64, 2004

4. Loeve F, van Ballegooijen M, Snel P and Habbema JD: Colorectal cancer risk after colonoscopic polypectomy: a population-based study and literature search. Eur J Cancer 41: 416-422, 2005.

5. Koehler A, Bataille F, Schmid C, Ruemmele P, Waldeck A, Blaszyk H, Hartmann A, Hofstaedter F and Dietmaier W: Gene expression profiling of colorectal cancer and metastases divides tumours according to their clinicopathological stage. J Pathol 204: 65-74, 2004.

6. Kolonel LN, Altshuler D and Henderson BE: The multiethnic cohort study: exploring genes, lifestyle and cancer risk. Nat Rev Cancer 4: 519-527, 2004.

7. Ohtsuka M, Ling H, Doki Y, Mori M and Calin GA: MicroRNA processing and human cancer. J Clin Med 4: 1651-1667, 2015

8. Wang J, Song YX, Ma B, Wang JJ, Sun JX, Chen XW, Zhao JH, Yang YC and Wang ZN: Regulatory roles of non-coding RNAs in colorectal cancer. Int J Mol Sci 16): 19886-19919, 2015.

9. Anwar SL and Lehmann U: MicroRNAs: emerging novel clinical biomarkers for hepatocellular carcinomas. J Clin Med 4: 1631-1650, 2015.

10. Kedmi M, Sas-Chen A and Yarden Y: MicroRNAs and growth factors: an alliance propelling tumor progression. J Clin Med 4: 1578-1599, 2015.

11. Han F, He J, Li F, Yang J, Wei J, Cho WC and Liu X: Emerging roles of nicroRNAs in EGFR-targeted therapies for lung cancer. Biomed Res Int 2015: 672759, 2015.

12. Croner RS, Foertsch T, Brueckl WM, Guenther K, Siebenhaar R, Stremmel C, Matzel KE, Papadopoulos T, Kirchner T, Behrens J, et al: Common denominator genes that distinguish colorectal carcinoma from normal mucosa. Int J Colorectal Dis 20: 353-362, 2005.

13. Raetz EA and Moos PJ: Impact of microarray technology in clinical oncology. Cancer Invest 22: 312-320, 2004.

14. Chiu ST, Hsieh FJ, Chen SW, Chen CL, Shu HF and Li H: Clinicopathologic correlation of up-regulated genes identified using cDNA microarray and real-time reverse transcriptionPCR in human colorectal cancer. Cancer Epidemiol Biomarkers Prev 14: 437-443, 2005.

15. Nambiar PR, Nakanishi M, Gupta R, Cheung E, Firouzi A, Ma XJ, Flynn C, Dong M, Guda K, Levine J, et al: Genetic signatures of high- and low-risk aberrant crypt foci in a mouse model of sporadic colon cancer. Cancer Res 64: 6394-6401, 2004. 
16. Mariadason JM, Arango D, Shi Q, Wilson AJ, Corner GA, Nicholas C, Aranes MJ, Lesser M, Schwartz EL and Augenlicht LH: Gene expression profiling-based prediction of response of colon carcinoma cells to 5-fluorouracil and camptothecin. Cancer Res 63: 8791-8812, 2003.

17. Neviani P and Fabbri M: Exosomic microRNAs in the tumor microenvironment. Front Med (Lausanne) 2: 47, 2015.

18. Eisinger F, Roussel C, Morère JF and Viguier J. Cancer screening: reaching the limits or terra incognita? Lessons from the EDIFICE surveys. Eur J Cancer Prev 20 (Suppl 1): S42-S44, 2011.

19. Peters U, Bien $S$ and Zubair N: Genetic architecture of colorectal cancer. Gut 64: 1623-1636, 2015.

20. Lu J, Getz G, Miska EA, Alvarez-Saavedra E, Lamb J, Peck D, Sweet-Cordero A, Ebert BL, Mak RH, Ferrando AA, et al: MicroRNA expression profiles classify human cancers. Nature 435: 834-838, 2005.

21. Ng EK, Chong WW, Jin H, Lam EK, Shin VY, Yu J, Poon TC, $\mathrm{Ng}$ SS and Sung JJ: Differential expression of microRNAs in plasma of colorectal cancer patients: a potential marker for colorectal cancer screening. Gut 58: 1375-1381, 2009.

22. Wu CW, Ng SS, Dong YJ, Ng SC, Leung WW, Lee CW, Wong YN, Chan FK, Yu J and Sung JJ: Detection of miR-92a and miR-21 in stool samples as potential screening biomarkers for colorectal cancer and polyps. Gut 61: 739-745, 2011.

23. Schetter AJ, Leung SY, Sohn JJ, Zanetti KA, Bowman ED, Yanaihara N, Yuen ST, Chan TL, Kwong DL, Au GK, et al: MicroRNA expression profiles associated with prognosis and therapeutic outcome in colon adenocarcinoma. JAMA 299: 425-436, 2008.

24. Ruddon R: Cancer Biology. Oxford University Press, New York, NY, 2007.

25. Corvinus FM, Orth C, Moriggl R, Tsareva SA, Wagner S, Pfitzner EB, Baus D, Kaufmann R, Huber LA, Zatloukal K, et al: Persistent STAT3 activation in colon cancer is associated with enhanced cell proliferation and tumor growth. Neoplasia 7: $545-555,2005$

26. Chekulaeva M and Filipowicz W: Mechanisms of miRNAmediated post-transcriptional regulation in animal cells. Curr Opin Cell Biol 21: 452-460, 2009.

27. Iorio MV and Croce CM: MicroRNA dysregulation in cancer: diagnostics, monitoring and therapeutics. A comprehensive review. EMBO Mol Med 4: 143-159, 2012.

28. Li J, Dong X, Wang Z and Wu J: MicroRNA-1 in cardiac Diseases and cancers. Korean J Physiol Pharmacol 18: 359-363, 2014.

29. Datta J, Kutay H, Nasser MW, Nuovo GJ, Wang B, Majumder S, Liu CG, Volinia S, Croce CM, Schmittgen TD, et al: Methylation mediated silencing of MicroRNA-1 gene and its role in hepatocellular carcinogenesis. Cancer Res 68: 5049-5058, 2008.

30. Hirai H, Verma M, Watanabe S, Tastad C, Asakura Y and Asakura A: MyoD regulates apoptosis of myoblasts through microRNA-mediated downregulation of Pax3. J Cell Biol 191: 347-365, 2010

31. Nasser MW, Datta J, Nuovo G, Kutay H, Motiwala T, Majumder S, Wang B, Suster S, Jacob ST and Ghoshal K: Down-regulation of micro-RNA-1 (miR-1) in lung cancer. Suppression of tumorigenic property of lung cancer cells and their sensitization to doxorubicin-induced apoptosis by miR-1. J Biol Chem 283 : 33394-33405, 2008

32. Yoshino H, Chiyomaru T, Enokida H, Kawakami K, Tatarano S, Nishiyama K, Nohata N, Seki N and Nakagawa M: The tumoursuppressive function of miR-1 and miR-133a targeting TAGLN2 in bladder cancer. Br J Cancer 104: 808-818, 2011.
33. Nohata N, Sone Y, Hanazawa T, Fuse M, Kikkawa N, Yoshino H, Chiyomaru T, Kawakami K, Enokida H, Nakagawa M, et al: miR-1 as a tumor suppressive microRNA targeting TAGLN2 in head and neck squamous cell carcinoma. Oncotarget 2: 29-42, 2011.

34. Xu Q, Liu LZ, Qian X, Chen Q, Jiang Y, Li D, Lai L and Jiang BH: MiR-145 directly targets p70S6K1 in cancer cells to inhibit tumor growth and angiogenesis. Nucleic Acids Res 40: 761-774, 2012.

35. Götte M, Mohr C, Koo CY, Stock C, Vaske AK, Viola M, Ibrahim SA, Peddibhotla S, Teng YH, Low JY, et al: miR-145-dependent targeting of junctional adhesion molecule A and modulation of fascin expression are associated with reduced breast cancer cell motility and invasiveness. Oncogene 29: 6569-6580, 2010.

36. Akao Y, Nakagawa Y, Iio A and Naoe T: Role of microRNA-143 in Fas-mediated apoptosis in human T-cell leukemia Jurkat cells. Leuk Res 33: 1530-1538, 2009.

37. Gao W, Yu Y, Cao H, Shen H, Li X, Pan S and Shu Y: Deregulated expression of miR-21, miR-143 and miR-181a in non small cell lung cancer is related to clinicopathologic characteristics or patient prognosis. Biomed Pharmacother 64: 399-408, 2010.

38. Clapé C, Fritz V, Henriquet C, Apparailly F, Fernandez PL, Iborra F, Avancès C, Villalba M, Culine S and Fajas L: miR-143 interferes with ERK5 signaling, and abrogates prostate cancer progression in mice. PLoS One 4: e7542, 2009.

39. Lee NP, Poon RT, Shek FH, Ng IO and Luk JM: Role of cadherin-17 in oncogenesis and potential therapeutic implications in hepatocellular carcinoma. Biochim Biophys Acta 1806: $138-145,2010$

40. Liu LX, Lee NP, Chan VW, Xue W, Zender L, Zhang C, Mao M, Dai H, Wang XL, Xu MZ, et al: Targeting cadherin-17 inactivates Wnt signaling and inhibits tumor growth in liver carcinoma. Hepatology 50: 1453-1463, 2009.

41. Ibrahim AF, Weirauch U, Thomas M, Grünweller A, Hartmann RK and Aigner A: MicroRNA replacement therapy for miR-145 and miR-33a is efficacious in a model of colon carcinoma. Cancer Res 71: 5214-5224, 2011.

42. Grzybowska-Izydorczyk O and Smolewski P: The role of the inhibitor of apoptosis protein (IAP) family in hematological malignancies. Postepy Hig Med Dosw (Online) 62: 55-63, 2008 (In Polish).

43. Herman MD, Moche M, Flodin S, Welin M, Trésaugues L, Johansson I, Nilsson M, Nordlund P and Nyman T: Structures of BIR domains from human NAIP and cIAP2. Acta Crystallogr Sect F Struct Biol Cryst Commun 65: 1091-1096, 2009.

44. Verhagen AM, Coulson EJ and Vaux DL: Inhibitor of apoptosis proteins and their relatives: IAPs and other BIRPs. Genome Biol 2: reviews3009-reviews3009.10, 2001.

45. Davoodi J, Ghahremani MH, Es-Haghi A, Mohammad-Gholi A and Mackenzie A: Neuronal apoptosis inhibitory protein, NAIP, is an inhibitor of procaspase-9. Int J Biochem Cell Biol 42: 958-964, 2010.

46. Dubrez-Daloz L, Dupoux A and Cartier J: IAPs: more than just inhibitors of apoptosis proteins. Cell Cycle 7: 1036-1046, 2008.

47. Franchi L, Eigenbrod T, Munoz-Planillo R and Nunez G: The inflammasome: a caspase-1-activation platform that regulates immune responses and disease pathogenesis. Nat Immunol 10: 241-247, 2009.

48. Pekow JR, Dougherty U, Mustafi R, Zhu H, Kocherginsky M, Rubin DT, Hanauer SB, Hart J, Chang EB, Fichera A, et al: miR-143 and miR-145 are downregulated in ulcerative colitis: putative regulators of inflammation and protooncogenes. Inflamm Bowel Dis 18: 94-100, 2012. 